An ESRC Research Group

\title{
Adaptation, Poverty and Well-Being: Some Issues and Observations with Special Reference to the Capability Approach and Development Studies
}

\section{GPRG-WPS-081}

\author{
David A. Clark
}

\section{Global Poverty Research Group}

Website: http://www.gprg.org/

The support of the Economic and Social Research Council (ESRC) is gratefully acknowledged. The work was part of the programme of the ESRC Global Poverty Research Group. 


\title{
Adaptation, Poverty and Well-Being: \\ Some Issues and Observations with Special Reference to the Capability Approach and Development Studies
}

\author{
2 September 2007 \\ David A. Clark \\ Global Poverty Research Group, \\ Brooks World Poverty Institute and \\ Institute for Development Policy and Management \\ University of Manchester, UK
}

Email:

David_A_Clark@hotmail.com 


\title{
Adaptation, Poverty and Well-Being: \\ Some Issues and Observations with Special Reference to the Capability Approach and Development Studies ${ }^{1}$
}

\author{
David A. Clark
}

\begin{abstract}
The idea that people adapt to poverty and deprivation by suppressing their wants, hopes and aspirations has gained a lot of currency in development ethics. While the 'adaptation problem' is often cited as one of the primary arguments for abandoning utility based concepts of well-being in favour of the capability approach, it also has serious implications for the capability approach and development studies generally. These implications are not normally discussed or acknowledged in the well-being and development literature. Fortunately for development studies, the available evidence suggests that adaptation is not ubiquitous. Moreover, where adaptation occurs, there is some evidence to suggest that it takes a different - and far less damaging - form than the type discussed in work on human well-being and development.
\end{abstract}

Key words - Adaptation, Aspirations, Capability, Democracy and participation, Human values, Paternalism, Poverty and human development, Utility and Well-being.

(C) David A. Clark September 2007

\footnotetext{
${ }^{1}$ This paper is intended to highlight some key issues relating to adaptation, poverty and wellbeing from a development studies perspective. At times some arguments are left hanging, partly through lack of data and partly through the complexity of following through every part of the argument, in areas where much is still under debate.
} 


\section{Introduction}

Over the last decade Amartya Sen's capability approach (CA) has emerged as a leading alternative to mainstream economic frameworks for conceptualising and assessing human well-being and development. A central objective of the CA - like the basic needs approach before it - is to put people rather than (material) things at the centre of the international development agenda. Thus, poverty, inequality and well-being are analysed in terms of the capability or freedom people have to achieve the various 'beings' and 'doings' they have reason to value (e.g. Sen, 1999). In this framework development involves the expansion of human capabilities rather than economic growth, which is only one possible means to this end (Drèze and Sen, 1989; Sen, 1999). ${ }^{2}$

The CA has become increasingly influential in recent years and has spawned a growing literature in economics and social science as well as philosophy (see Clark, 2006a; Robeyns, 2006, 2007). In particular, it has revitalized much of contemporary development studies by providing the conceptual foundations for the human development movement (see Fukuda-Parr, 2003, esp. pp. 302-303; Alkire, 2002). ${ }^{3}$ Most notably, perhaps, it has inspired the United Nations Human Development Reports (published annually since 1990) and has given birth to the Human Development Index (HDI), which despite well known limitations provides a broader measure of development than GNP for policy purposes (see Sen, 2006a).

\footnotetext{
2 The CA can be traced back to Sen's Tanner Lecture 'Equality of What?' delivered at Stanford University in 1979 (see Sen, 1980). The CA was first outlined in detail in Sen's (1985a) book Commodities and Capabilities. See also Sen (1987b), Nussbaum and Sen (1993), Nussbaum and Glover (1995), Sen (1999), Nussbaum (2000), Alkire (2002) and Clark (2002b), among many others. For brief introductions to the CA see Sen (1990; 1993a), Saith (2001) and Clark (2006a). 3 See Haq (1995), Fukuda-Parr and Kumar (2003) and Qizilbash (2006b) on the human development movement.
} 
One reason for favouring the CA over economic concepts of well-being (based on welfare or utility) relates to the adaptation argument. As we will see adaptation - insofar as it exists - creates serious problems for all three variants of utility: namely, utility construed as happiness, desire fulfilment or choice. On closer inspection, however, adaptation also seems to have consequences for the CA and development studies more generally. The primary objective of this paper is to consider more fully the implications and the consequences of adaptation for development ethics (including the CA) and development policy and practice. The conclusion is fairly startling: namely, that adaptation in various forms and guises spells potential doom not just for utility and welfare economics, but for the CA and much of development studies as well. Fortunately for development studies, a brief survey of the available evidence suggests that adaptation is not ubiquitous. Moreover, where adaptation does occur, there is some evidence (from econometric studies of panel data) to suggest that it often takes a different and more benign form than the type suggested in the well-being and development literature.

\section{Adaptation}

There is a vast literature on adaptation in economics, social psychology and philosophy (see Frederick and Loewenstein, 1999, inter alia). Early discussions of adaptation can be found in John Stuart Mill's Utilitarianism and Karl Marx's analysis of 'false consciousness’ (see Bottomore, 1983; Qizilbash, 2006a; Sen, 2006b). More recently the idea that aspirations adjust 'to what is seen as possible' has been discussed by Jon Elster 
(1983, p.22). ${ }^{4}$ While Elster's notion of adaptation is fairly broad and inclusive for our purposes, ${ }^{5}$ it is possible to distinguish between different types and forms of adaptation. It is worth keeping this in mind, as the notion of adaptation is normally used in one particular and fairly specific sense by advocates of the CA and proponents of human well-being alike.

During the course of this paper it will be necessary to distinguish between different concepts of adaptation. No systematic attempt, however, will be made to identify, clarify and catalogue the many different notions of adaptation found in various literatures. ${ }^{6}$ Instead, this paper will focus on the concepts that seem most pertinent for development studies. In consequence, a large part of this paper is concerned with the 'adaptation problem' as identified by advocates of the CA and human development movement (see Qizilbash, 2006c). The adaptation problem refers to the possibility that people's aspirations and desires are malleable and 'can "adapt" in various ways to the straitened circumstances in which they live’ (ibid., p. 83). A more specific and manipulative form of adaptation can occur through social conditioning or cultural and religious indoctrination. These two concepts can be distinguished from a more general form of adaptation much discussed in philosophy and economics that acknowledges 'human limitations' in terms

\footnotetext{
${ }^{4}$ Other contributions include Nussbaum (2001), Sandven (1999a,b), Qizilbash (1997a, 2006a,c) and Teschl and Comim (2005).

5 'Adaptation, in its broadest sense, refers to any action, process or mechanism that reduces the effects (perceptual, physiological, attentional, motivational, hedonic, and so on) of a constant repeated stimulus' (Frederick and Loewenstein, 1999, p.302).

${ }^{6}$ This would be a useful project in itself, although it is clearly beyond the scope and purpose of the present paper.
} 
of the capacity to acquire, retain and process relevant information form making informed judgments and rational choices (see Qizilbash, 2006c, inter alia). ${ }^{7}$

Another key distinction employed in this paper refers to the causal mechanisms that drive adaptation. Notice that the process of adjusting aspirations 'to what is seen as possible' can occur in two fundamentally different ways. The first typically involves adjusting aspirations downwards to reflect disadvantaged circumstances and hardship. This, of course, is the notion of adaptation frequently invoked in the capability and human development literature. The second type of adaptation involves adjusting aspirations upwards to reflect new opportunities and what others (most notably the person's peers or reference group) have managed to achieve. ${ }^{8}$ This notion of adaptation is closely related to recent empirical work on happiness or subjective well-being in economics and psychology (e.g. Stutzer, 2004; Easterlin, 2001, inter alia). It goes without saying that these types of adaptation have very different implications for development ethics and practice. I shall focus on the first type of adaptation in the following two sections before turning to the second.

\footnotetext{
${ }^{7}$ There are many other forms of adaptation that have not been extensively discussed in the development literature. For example, diminished aspirations due to straitened circumstances or social conditioning are rarely distinguished from 'normal' processes of socialization (Qizilbash, 2006c, p. 92) or 'character planning' (Elster, 1982, p. 224), which both preserve autonomy. In fact, some texts give the impression that processes of socialization - particularly under capitalism - are ubiquitously harmful (e.g. Crocker and Linden, 1998; Gasper, 2002). Jon Elster (1982) distinguishes between several different notions of adaptation some of which are not discussed in this paper.

${ }^{8}$ Adaptation could conceivably occur through either one of these mechanisms to varying degrees or through both mechanisms as people become better or worse off. The only way of distinguishing between them empirically is through the analysis of panel data which allows us to distinguish between changes in actual and aspired variables.
} 
Before proceeding it is important to clarify what is, and what is not, being claimed about the first type of adaptation. The basic proposition is that this form of adaptation, insofar as it exists, has serious consequences for development ethics and practice. It is not being claimed that this type of adaptation is necessarily a bad thing - although it may be regarded as intrinsically 'bad' insofar as it robs individuals of the autonomy to make rational choices (e.g. Elster, 1983). Indeed, given the large number of chronically poor and severely deprived people in the world, it is only prudent to wonder how much suffering and misery there would be in the absence of adaptation.

\section{Implications for Development Ethics}

Social scientists and philosophers often refer to 'adaptation' and the dilemmas it poses for ethical theory and social evaluation. In the context of development, the notion of adaptation is most frequently invoked in the rapidly expanding literature on well-being and human development. In particular, it is often cited as one of the chief arguments for abandoning utility-based concepts of well-being in favor of a capability - or basic needs - approach to development (see Crocker, 1992 for a brief overview). ${ }^{9}$ The case against utility has been forcefully made by Amartya Sen (in many places), whose 'adaptation' argument has special significance for development:

\footnotetext{
${ }^{9}$ It is not the only argument for preferring the CA, however (see below).

The adaptation argument might also be used to justify falling back on an income or resource based approach to well-being. There are, however, strong arguments for preferring the CA. In particular, the CA recognizes that while income and resources are instrumentally important for promoting human well-being and development, there is not always a strong link between income and material things on the one hand and the realization of intrinsically valuable capabilities on the other (see Sen, 1985a; Crocker, 1992; Nussbaum, 2000; Clark,. 2002b, ch.2; 2006a).
} 
A thoroughly deprived person, leading a very reduced life, might not appear to be badly off in terms of the mental metric of utility, if the hardship is accepted with non-grumbling resignation. In situations of longstanding deprivation, the victims do not go on weeping all the time, and very often make great efforts to take pleasure in small mercies and cut down personal desires to modest - 'realistic' - proportions. The person's deprivation then, may not at all show up in the metrics of pleasure, desire fulfilment, etc., even though he or she may be quite unable to be adequately nourished, decently clothed, minimally educated and so on' (Sen, 1990, p.45).

The battered slave, the broken unemployed, the hopeless destitute, the tamed housewife, may have the courage to desire little, but the fulfilment of those disciplined desires is not a sign of great success and cannot be treated in the same way as the fulfilment of the confident and demanding desires of the better placed (Sen, 1987b, p.11). ${ }^{10}$

Insofar as utility levels provide unreliable and misleading proxies for human well-being, there is a strong case for looking directly at human achievement and capability instead (as Sen and others argue).

Another kind of adaptation discussed by Sen and others - often though not always in the context of development - involves various kinds of social conditioning, most notably religious and cultural forms of indoctrination (Nussbaum and Sen, 1989; Nussbaum and Glover, 1995; Nussbaum, 2000, inter alia). Sen is concerned that cultural and religious ideas may condition the poor and deprived to accept and even find justification for their lot in life (Sen, 1982, p.376; Sen and Williams, 1982, p.367). In one passage he remarks:

If a starving wreck, ravished by famine, buffeted by disease, is made happy through some mental conditioning (say, via the "opium of religion"), the person would be seen as doing well on [the] mental state perspective, but that would be quite scandalous (Sen, 1985b, p.188).

Social conditioning can also distort perceptions of relative needs, which can lead to disparities in the quality of life between different members of the household - most

\footnotetext{
${ }^{10}$ In a virtually identical passage Sen (1987a, p.46) attributes the same problem to the 'happiness' view of utility.
} 
notably between men and women or adults and children. Sen's estimates of sex and age bias in poverty underline this point (e.g. Sen, 1984, essay 13; 1985a, pp.81-104). ${ }^{11}$

A more subtle form of adaptation relates to the inability to acquire and process all the necessary information for making informed judgments. In the context of development it might be thought that the poor and deprived lack the necessary education, knowledge and experience to harbor grand desires or make rational choices. ${ }^{12}$ Such arguments provide further grounds for doubting the reliability of utility inspired ethics as guides to wellbeing. However, in an increasingly global and multicultural world it is no longer realistic to suppose that the poor and deprived lack sufficient knowledge about alternative life styles to make informed judgments. In the early twenty-first century it is virtually impossible to find an example of an 'untouched' culture or society. Even relatively

${ }^{11}$ Following the recent celebrations to mark the two hundredth anniversary of the abolition of the Atlantic Slave Trade, Richard Jolly has reminded me of 'the extreme and brutal process used to "break in" slaves, much like horses are broken-in. Such social conditioning sometimes appeared to involve a total psychological reconditioning, sometimes no more than a conscious and deliberate act of submission in response to overwhelming force' (personal communication). The long and diverse history of slavery also shows that individual acts of rebellion on the one hand and collective action and interaction on the other can awaken or reawaken the human spirit to opposition (for some pertinent examples see Rodriguez, 2007, inter alia). Ironically it has been estimated that more slaves are alive today than were taken from Africa during the Atlantic Slave Trade (Garstang, 2007). A relatively recent submission to the UN Commission on Human Rights by the NGO Anti-Slavery International documents the violence and coercion, social conditioning, societal pressure and lack of education or 'perceived alternatives' that help retain control over slaves in contemporary Niger (Anti-Slavery International, 2003). It follows that a lot could be learned from integrating the conceptual discussions of adaptation found in development ethics and philosophy with applied work on the social and psychological processes associated with slavery and emancipation.

12 Martha Nussbaum's version of the CA (in contrast to Sen's) places a strong emphasis on educating those who are going to participate in public discussions about the ends of life (e.g. Nussbaum, 2006). Some social theorists remain extremely skeptical of the role public reasoning and democracy can play in uncovering the capabilities people have reason to value (e.g. Deneulin, 2005). Doyal and Gough (1991) specify criteria (which include intellect, understanding and communication with others) for achieving the 'minimal autonomy' required for formulating needs. They propose juxtaposing the 'experiential knowledge' or ordinary people, cultures and societies (which do not actually feature in their work) with the codified knowledge of so called 'experts' to resolve disputes over needs (p. 141). 
isolated parts of Africa, Asia and Latin America have been touched by radio and television, if not by persistent migration. Moreover, despite often lacking a formal education, the available evidence from studies of human values (e.g. Alkire, 2002; Clark, 2002b; Clark and Qizilbash, 2007) and participatory poverty assessments (e.g. Narayan et al 2000, 2002) indicates that the poor and deprived are capable - and arguably just as capable as anyone else - of making rationale judgments and choices. As Robert Chambers (1997) has pointed out, one of the key lessons to follow from the countless number of participatory studies administered throughout the developing world is that 'they can do it' (p. 131). ${ }^{13}$

Adaptation also has serious consequences for the evaluation of inequality. Because the poor and disadvantaged learn to be satisfied with less than the more advantaged, standard utilitarian ethics typically discriminate against (in favor of) those at the bottom (top) of a distribution (see Sen, 1980; and Cohen, 1993 versus Sen, 1993a for further discussion). ${ }^{14}$ Notice that this kind of reasoning applies to many different forms of inequality including income inequality. Moreover, Sen (1992) shows that adaptation and the problem of ‘entrenched deprivation’ have particular significance for social divisions along the lines of class, community, caste and gender (esp. p.55). According to Sen the nature of these inequalities is best brought out by comparing differences in capabilities rather than

\footnotetext{
${ }^{13}$ It is therefore particularly ironic that some middle class intellectuals continue to believe they know best. Such views are especially common among philosophers and social theorists on the Left who have little - if any - direct contact with ordinary poor people. Arguably such beliefs amount to a new kind of 'false consciousness' not acknowledged or discussed in the well-being or development literature: namely, that some intellectuals are blissfully unaware that they 'do not always know best'.

${ }^{14}$ Sen is aware that there are more sophisticated forms of utilitarianism involving, for example, interpersonal scaling (e.g. Sen, 1980, pp.200-201), which can address social issues.
} 
utilities. Even a return to a utility inspired ethic 'as a supplement to the capability perspective would tend to wipe out - at least partially - the gains from the change, especially by undervaluing those capabilities which the chronically deprived dare not covet. The exercise of evaluation of capabilities cannot be left to the mere totalling of utilities generated by those capabilities. The difference can be quite far-reaching in the case of deep-rooted and resilient inequalities' (ibid, p. 55).

Ironically, it could be argued that Sen's CA to development may turn out to be just as susceptible as utility to the problem of adaptation and cultural indoctrination (Nussbaum, 1988, p.175; Qizilbash, 1997a, p.253; Sumner, 1996, pp.60-80). In essence, this is because Sen's CA appeals to democratic principles and a bottom up conception of the good (see Sen, 2004; 2005a; see also Alkire, 2002; Clark 2002b, 2006a). For Sen 'it is the people directly involved who must have the opportunity to participate in deciding what should be chosen', not local elites (political or religious) or cultural ‘experts’ (domestic or foreign) (Sen, 1999, pp.31-2). ${ }^{15}$ The discussion here relates to the identification of human values, rather than mere preferences or wants (or even subjective well-being, as defined in the psychological literature on development). Yet there is no prima facie reason to suppose that human values (on the surface at least, i.e. when reported) are any less malleable than preferences, wants or satisfaction. The substantive freedoms people have reason to value might be suppressed and muffled by the same psychological

\footnotetext{
${ }^{15}$ Sen makes these remarks in the context of discussing possible tensions between traditional values and the process of economics and social change. It is clear, however, that Sen favours a form of democracy that guarantees the liberty of individuals to 'live whatever kind of life [they] desire' (Sen, 2006b, p.89).
} 
processes that make utility an unreliable guide to poverty, inequality and well-being generally.

In practice, however, human values may turn out to be less malleable than feelings and aspirations. The poor and deprived may learn to be happy and content with relatively little and may reduce their wants, hopes and aspirations to modest - 'realistic' proportions in an effort to avoid bitter disappointment without loosing sight of their apparent disadvantage or compromising their capacity to value and weigh different forms of life. My own experience from fieldwork in rural and urban parts of South Africa suggests that while the poor and disadvantage often report high levels of happiness and life satisfaction (implying adaptation in terms of subjective well-being), they are still capable of imagining, articulating and demanding a substantially better or 'good' form of life (Clark, 2002b; Clark and Qizilbash, 2007; see also Moller, 1996). ${ }^{16}$

The way in which human values are uncovered is crucial. In the latest version of Sen's CA, the capabilities or freedoms people have 'reason to value' emerge through a process of public reasoning and discussion (1999, esp. pp. 30, 110 and 152-3; 2004; 2005a). This process involves open criticism of a range of ethical claims drawn from different cultures and societies (see also Nussbaum and Sen, 1989; Sen, 2005a,b). Insofar as value judgments are informed by intercultural exchanges and 'improved' through public

\footnotetext{
${ }^{16}$ Ultimately the question of whether values or aspirations are more or less susceptible to adaptation than subjective well-being becomes an empirical issue. Moller (1996), Clark (2002b; 2003) and Clark and Qizilbash (2007) present evidence to suggest that values and aspirations have not been crushed by the harsh realities of life in South Africa (see also below).
} 
reasoning, we can expect them to be more reliable (and less susceptible to adaptation). ${ }^{17}$ Many different forms of public discussion and deliberation are possible, however. Moreover, Sen has been criticized for 'choosing not to specify the possible range of procedures by which valuational issues are to be resolved or by which information on valuations is to be obtained' (Alkire, 2002, p. 13). More recently, David Crocker (2006) has attempted to augment the CA with a detailed account of 'deliberative democracy'. Such an approach is promising in theory, ${ }^{18}$ but in practice needs to confront and overcome a range of blatant inequalities ranging from the exclusion of weak and vulnerable groups on the one hand to inequalities in power and voice on the other (see also Deneulin, 2005; Young, 2006). ${ }^{19}$ Thus, some social values may be displaced by a new form of adaptation that privileges the ethical beliefs of the powerful and advantaged. Even in cases where deliberative forms of democracy function well and everyone's voice

\footnotetext{
${ }^{17}$ Sen (2005a, p. 160) writes 'public discussion and reasoning can lead to a better understanding of the role, reach and significance of particular capabilities'.

${ }^{18}$ I do not wish to be misread here. Democracy is an ideal to be strived for; not an unworkable idea that should abandoned.

${ }^{19}$ The pitfalls described here might include differences in people's capacity to make an argument for a particular point of view. I do not wish to imply, however, that professional philosophers or intellectuals will always 'win' the argument in question or be able to persuade the lay person of their 'enlightened' views. As I have been reminded by Mozaffar Qizilbash, there is no reason to suppose that the poor and disadvantaged are strangers to wisdom or reason. In fact, many amongst the poor and deprived are, in my experience, great thinkers and philosophers, even though their thoughts are not published in so called 'scholarly' journals. Crocker's (2006) discussion of the type of 'skills and virtues' deliberators ought to posses suggests that many poor and disadvantaged people might be excluded from public discussions!

Sen briefly comments on the importance of giving voice to the poor and disadvantaged in his introduction to The Argumentative Indian: 'It is sometimes asserted that the use dialectics is largely confined to the more affluent and more literate, and is thus of no value to the common people. The elitisism that is rampant in such beliefs is not only extraordinary, it is made more exasperating through the political cynicism and impassitivity it tends to encourage. The critical voice is the traditional ally of the aggrieved, and participation in arguments is a general opportunity, not a particularly specialized skill (like composing sonnets or performing trapeze acts)' (Sen, 2005b, p. xiii).
} 
is heard, there may be grounds for concern insofar as majority rule is allowed to trump individual values (see Sugden, 2006). ${ }^{20}$

So where does this leave us? In theory at least - if not in practice - both Sen's CA and utility construed in terms of happiness or desire fulfillment may be vulnerable to adaptation. Insofar as this is the case, these ethics will provide unreliable guides to poverty, inequality and well-being. But what of the revealed preference approach, which views utility as choice? Sen dismisses the choice based approach as 'a non-starter', on the grounds that people do not always choose in accordance with their own personal interests, but often wish to take account of wider concerns which may not coincide with personal well-being (Sen, 1985a, pp.18-20; 1987b, pp.12-13). Yet he does indicate that the adaptation argument does not apply to the choice based approach. Sen remarks that

much of what [I have] said about the desire interpretation of utility will apply [to the choice based approach] too, except, perhaps, the point about bias of the desire interpretation against the underdog in making interpersonal comparisons based on desire intensities' (Sen, 1987b, p.12, original emphasis).

In practice, however, many choices appear to be symptoms of poverty (see Qizilbash, 1997b; Clark, 2002b, p.44 and n.36). It is not just that aspirations or values adapt to reflect personal hardship; it is also plausible to suppose that people's capabilities and choices adjust too. As Mozaffar Qizilbash (1997a) has argued, people may develop various 'compensating abilities' in the face of hardship. For example, women who are relatively disadvantaged may work harder than men in order to achieve the same level of

\footnotetext{
${ }^{20}$ There is a great deal of confusion in the literature regarding Sen's views on this matter. Contrary to Sugden (2006), Sen is against permitting the 'collective tyranny' of the majority to override individual values and choices (Sen, 2006b, esp. p. 89).
} 
well-being. In cases where compensating abilities develop looking directly at human capability, behavior and choice will provide unreliable guides to well-being. It is worth emphasizing that the direction of the adaptation process is reversed here: the disadvantaged and deprived adjust their abilities upwards (instead of their desires downwards) to compensate for their relative disadvantage.

\section{Implications for Development Policy and Practice}

The adaptation argument also has potentially serious consequence for development policy and practice, although this point appears to be less well recognized in contemporary development discourse, possibly because of the gulf that divides philosophers and social theorists from applied development economists and practitioners. More specifically, the idea that wants, hopes and aspirations adapt to reflect personal hardship appears to undermine the case for listening to the voices of the poor, not to mention the entire participatory poverty research movement, which has grown into a vast industry over the last two or three decades and has come to represent a defining feature of contemporary development studies. ${ }^{21}$

The moral and practical case for listening to the voices of the poor has been recognized by philosophers and applied development thinkers alike. In the opening pages of The Cruel Choice, published over three decades ago, the father of modern development ethics, Denis A. Goulet (1971, pp.23-4) wrote:

\footnotetext{
${ }^{21}$ In this paper I set aside the fact that these voices may provide other types of useful information (e.g. factual information).
} 
Underdevelopment is shocking: the squalor, disease, unnecessary deaths, and hopelessness of it all! No man understands if underdevelopment remains for him a mere statistic reflecting low income, poor housing, premature mortality or underemployment. The most emphatic observer can speak objectively about underdevelopment only after undergoing, personally or vicariously, the "shock of underdevelopment". This unique culture shock comes to one as he is initiated to the emotions that prevail in the "culture of poverty" ... Chronic poverty is a cruel kind of hell, and one cannot understand how cruel that hell is merely by gazing upon poverty as an object. Unless the observer gains entry into the inner sanctum of these emotions and feels them himself, he will not understand the condition he seeks to abolish.

Development studies cannot be conducted in a vacuum (Clark, 2006b, p. xxxvi). As the quote from Goulet points out, there can be no substitute for experiencing poverty or encountering underdevelopment. ${ }^{22}$ For those analysts and practitioners from the Northern hemisphere (and arguably many upper class scholars from the Southern hemisphere) who have never known real hardship, the best available strategy for understanding 'the condition he [or she] seeks to abolish' is to engage directly with the experiences and views of the poor. ${ }^{23}$ As outsiders, it is important to remember that 'they' are the experts, not 'us'. It is far too easy to become complacent and to underestimate the value of the contribution the poor and deprived have to make. As the distinguished Cambridge anthropologist, Polly Hill, purportedly liked to remark '[w]e are so ignorant of the conditions of poverty in the developing world that we do not know how ignorant we are' (Gregory, 2006, p. 223).

\footnotetext{
${ }^{22}$ I do not wish to imply that the late Denis Goulet would agree with the substantive conclusions of this paper.

${ }^{23}$ Whether or not middle class researchers should strive to experience poverty themselves is a moot point. It is by no means clear that these experiences are transferable. Moreover, as Williamson (2003, p.26) points out we live in a 'class culture and it is typical of the upper middle class to want all experience for themselves, even poverty: what they are incapable of doing is just shutting up and listening'.
} 
In a similar vein, Robert Chambers (1997), one of the most influential champions of the poor, asks 'whose reality counts?' In a range of papers and books dating from the early 1980s, Chambers and his associates at the University of Sussex have argued the case for 'putting the last first ${ }^{\text {,24 }}$ and have developed a range of participatory methodologies for including and empowering the poor in the development process. In recent years this work has revolutionized development studies and has forced many of us to confront uncomfortable ethical questions about how 'we' do development. Perhaps the clearest indication of Chambers's influence can be found in the rapid expansion of participatory poverty assessments in developing countries from the early 1990s (for a list see Narayan et al, 2000, appendix 8), although on the basis of the World Bank's three volume summary, Voices of the Poor, much remains to be learned about 'putting the first last'. ${ }^{25}$ Yet these voices do contain important policy lessons. Moreover, thanks to Robert Chambers and others, at least some of those with authority and power are now listening.

In a related context I have called on development ethicists to follow the example suggested by Goulet by advocating a new form of 'empirical philosophy' for understanding poverty and well-being (Clark, 2002a, p.834). The logic of the adaptation argument, however, is that we should retreat into social theory and high philosophy. The empirics of the subject only blur the issue. Such logic can be used to champion procedural accounts of the good based on reason alone, which are inevitably divorced

\footnotetext{
${ }^{24}$ More recently Chambers (1997) has presented the case for 'putting the first last', which he says is harder to accomplish (p.2). Chambers has not considered the adaptation argument in his extensive writings on participatory development (personal communication with Robert Chambers, 21 July 2007).

${ }^{25}$ One bone of contention is that the World Bank has asserted copyright over the voices of the poor. Another bone of contention is that these voices have been interpreted through the lens of social capital and used to legitimize the Bank’s development framework.
} 
from local realities and often open the door to paternalism. As Clark (2002b; 2003; 2005) and Okin (2003) have both shown, bottom up perceptions of poverty and well-being differ in several crucial respects from the abstract concepts commonly found in the theoretical literature.

\section{Empirical Evidence}

As we have seen a great deal hangs on the adaptation argument. In fact, far more depends on adaptation than is generally recognized or acknowledged in work on human wellbeing and development. The empirical evidence relating to adaptation therefore requires careful consideration before turning to a broader discussion of the implications for development in the following section.

Sen provides relatively little hard evidence to support the adaptation argument in his extensive writings on the CA and human development. In some of his early contributions he briefly refers to evidence from a post famine survey administered in Singur, India, in 1944, which suggests significant disparities between the externally observed health of widows and their own subjective impressions of their physical states (Sen, 1984, p.309; 1985a, pp.82-3). ${ }^{26}$ Martha Nussbaum (2000), on the other hand, has provided detailed accounts of adaptation through qualitative life-histories of two impoverished Indian women, who were the victims of prolonged domestic violence and exploitation.

\footnotetext{
${ }^{26}$ Nussbaum (2000, pp.113-4) describes a similar case involving malnourished women living in unsanitary conditions in the desert outside Mahabubnagar, Andhra Pradesh. Nussbaum observes that these women were resigned to their fate until a government 'consciousness-raising' initiative generated anger and discontent and spurred demands for clean water, electricity and health workers, inter alia. In related writings, Sen (1993b; 2002) has argued that self reported morbidity has serious limitations and can be extremely misleading.
} 
According to Nussbaum both of these women accepted their predicament without question or complaint as 'part of a women's lot in life', which seems to imply that 'there is something wrong with their preferences’ (pp. 112-113). Only after these women were released from their abusive relationships were they able to recognize that their rights had been violated. While these narratives are powerful and compelling, they only provide anecdotal evidence of adaptation, as they are based on an exceptionally small sample (two case studies) drawn from a single country.

The broader empirical evidence relating to adaptation is not easy to interpret (see Diener et al 1999; Frederick and Loewenstein, 1999). At best there is only mixed evidence to support the hypothesis that people suppress their aspirations in the light of personal hardship and deprivation. By the same token, however, there is also plenty of evidence particularly from more sophisticated econometric studies based on panel data - to suggest that people adjust aspirations upwards in the light of previous achievements or social comparisons with others.

Many empirical studies have found a weak positive relationship between income and aspirations or life satisfaction using cross section data (see Easterlin, 2001, pp.467-9; Frey and Stutzer, 2002). ${ }^{27}$ These studies suggest that 'happiness increases with absolute income, ceteris paribus, but not proportionately and at a diminishing rate' (Kingdon and Knight, 2006, pp. 1200-1201). The apparent association between income and happiness tends to weaken if controls for other variables (such as unemployment, education and health) are introduced. In practice, psychologists have tended to argue that a diverse

\footnotetext{
${ }^{27}$ The classic reference is Easterlin (1974).
} 
range of factors not necessarily associated with income tend to influence happiness including personal character traits, relative position in society, history, meaningful personal relationships, self-realization and respect for others, inter alia (e.g. Ryff, 1989; Kahneman et al., 1999; Diener et al., 1999; Diener and Suh, 2000; Ryan and Deci, 2001; Camfield and Skevington, forthcoming). In contrast economists have tended to emphasize the link between income on the one hand and aspirations and happiness on the other (Frey and Stutzer, 2000; Easterlin, 2001). One paradox, however, is that the association between income and happiness vanishes if cross section data is combined with lifecycle analysis. In short, people do not become happier on average over the course of their life even though their incomes tends to rise (Easterlin, 2001, pp.469-71).

In recent years more sophisticated econometric studies that use panel data to analyze adaptation have emerged (e.g. Stutzer, 2004; Burchardt, 2005). These studies are largely confined to European and US datasets and typically focus on income and expenditure. ${ }^{28}$ In contrast to studies based on cross section data (often including data relating to multiple points in time), these studies attempt to track the same individuals and households over time. These studies are therefore able to look at how changes in actual income are associated with changes in income aspirations and subjective well-being. This is immensely helpful for the task in hand, as it makes it possible to distinguish between the upward and downward forms of adaptation identified above.

\footnotetext{
${ }^{28}$ One exception is Chan et al (2002), who uses two wave panel data for Singapore and Taiwan to show that actual income and changes in income are strongly related to changes in perceptions of income adequacy. There are also examples of longitudinal studies of adaptation in other (nonincome) domains such as unemployment (e.g. Winkelman and Winkelman, 1998) and health (see Frederick and Loewenstein, 1999).
} 
A notable example of such a study is Burchardt (2005), who provides one of the only econometric analyses of adaptation linked to the CA. ${ }^{29}$ On the basis of the first ten waves of the British Household Panel Survey, Burchardt found that:

- People who have experienced a fall in income since the previous year are less satisfied than those with a constant income, suggesting that life satisfaction is related to previous experience;

- People who have experienced an increase in income over the last year are less satisfied than those who have a steady income - a result that runs counter to conventional wisdom; and

- Over a longer time frame (ten years), those who have experienced falling income trajectories are significantly less satisfied than those with long-run stable incomes, while those who have experienced rising income trajectories are no more satisfied than those with relatively stable long-run incomes.

Stutzer (2004) models the relationship between subjective well-being on the one hand, and income and aspirations on the other hand (see also Easterlin, 2001). On the basis of Swiss data from the early 1990s and supplementary data from the first two waves of the Swiss Household Panel Survey conducted in 1999 and 2000, Stutzer finds that higher income aspirations reduce subjective well-being or life satisfaction, ceteris paribus. He also demonstrates that income aspirations increase with previous income and relative income. In order to explain these results, Stutzer postulates that:

\footnotetext{
${ }^{29}$ In addition some unpublished studies of adaptation that make use of time series data have been presented at various HDCA conferences since 2001 (http://cfs.unipv.it/sen/index.html). Some of these papers are not readily available.
} 
- Due to the process of 'hedonic adaptation', increases in income or consumption only produce temporary increases in satisfaction. As people become accustomed to higher consumption, the extra satisfaction derived from this activity wears off.

- Income aspirations are driven by upward comparisons with socially significant others (the reference group). Aspirations therefore tend to exceed the level of income reached.

Together hedonic adaptation and social comparisons encourage ever higher income aspirations, which in turn checks long term subjective well-being as economic prosperity rises. $^{30}$

Of course poverty, well-being and human development are multidimensional and relate to a range of capabilities. Several attempts have been made to study adaptation in other (non-income) contexts. In particular, Diener et al (1999, p.286) concludes that 'considerable evidence exists that contradicts the "hedonic treadmill” theory that people completely and rapidly adapt to all circumstances'. Drawing on Frederick and Loewenstein (1999) survey of the psychology literature they observe 'that people adapt rapidly to some conditions (e.g., imprisonment and rises in income), slowly to other conditions (e.g., the death of a loved one), and not at all to other conditions (e.g., the pleasures of eating and the avoidance of noise)' (Diener et al., 1999, p. 286). This 'puzzle for adaptive theory’ has recently been picked up by Easterlin (2005) in economics, who shows that aspirations for material goods tend to rise with consumption, but aspirations for marriage and children do not change much with actual circumstance.

${ }^{30}$ Crucially, subjective well-being depends on the 'gap between aspiration and achievement' (Stutzer, 2004, p.91). This gap is repeatedly closed following a rise in current income, as people adapt to new consumption levels and endeavour to keep up with the rest of society. 
A first attempt to provide a multidimensional analysis of adaptation in a developing country context has been made by Barr and Clark (2006) and Clark and Qizilbash (2007) using data from a survey on The Essentials of Life, which was administered in three poor communities in South Africa in 2001. These papers use various methodologies to compare actual circumstances (or living conditions) with aspirations (responses to questions about what a typical person needs to 'get by' or 'live well') in various dimensions. Clark and Qizilbash (2007) focus on the housing, health and education domains and show that those living in the most straitened conditions in a particular dimension are not necessarily those who endorse the lowest required minimum to 'get by' in that dimension. In fact, in the case of health care, nearly 90 percent of people in the worst off category (no access to health care during their last serious illness) thought a clinic, public hospital or better are necessary for a person to 'get by'. ${ }^{31}$ Barr and Clark (2006) present similar findings using econometric techniques for income, education and health. They argue that preliminary results suggest a positive relationship between actual and aspired income and education, but a negative relationship between actual and aspired health. More work, however, is required to allow for social context (by controlling for reference group effects) and to establish causal relationships.

\section{Discussion}

As we have seen the available evidence only provides limited support for the adaptation argument and is not always easy to interpret. At the micro level, it is possible to find

\footnotetext{
${ }^{31}$ The available options respondents were asked to choose between were: 'no health care', 'traditional healer, family friend', 'clinic, public hospital, shop', 'pharmacy visit by PHC nurse' and 'private doctor'.
} 
examples of individuals and groups who have adapted to poverty and disadvantaged circumstances (as Martha Nussbaum has done). Of course, it is equally possible to find examples of people and communities that have not systematically adapted to grinding poverty and deprivation (Clark, 2002b, ch.4; Clark and Qizilbash, 2007). More generally, there is considerable evidence to suggest that people adapt to changes in some circumstances, but not to changes in other circumstances. In cases where people adapt, aspirations typically adjust to varying degrees and over different periods of time. The causal mechanisms behind these processes and the reasons why people adapt in some contexts (dimensions) rather than others are not well understood. Nonetheless, the fact that adaptation can occur is deeply worrying for ethical theory and social evaluation. All that is required is for some people to adapt sometimes for the calculus of utility (and many other metrics of well-being) to become distorted and muffled. ${ }^{32}$

The most detailed and convincing evidence of adaptation comes from studies of income and consumption. Multiple studies based on cross section data suggest a weak positive correlation between income and aspirations. This is consistent with adaptation, although it is not possible to say whether people are adapting to financial poverty (by cutting down their aspirations) or higher incomes (by raising their aspirations). Notice, however, that adaptation is not a comprehensive process, as changes in income typically translate into

\footnotetext{
32 This point appears to apply to a broad range of ethical theories including the revealed preference approach and democratic versions of the CA, as people's behavior, abilities and values may adjust too. However, arguments are presented below to suggest that the type of adaptation that typically occurs is less problematic from the standpoint of investigating human values. Incidentally, falling back on non-democratic (top down) accounts of human capabilities or needs is unlikely to improve matters, as so called 'experts' and ethical theorists may themselves be suffering from an acute bout of false consciousness (see note 13).
} 
proportionately smaller changes in aspirations. ${ }^{33}$ Insofar as people adapt to poverty and hardship there may be a case for amplifying the voices of the poor. This would involve attempting to correct for any shortfall in aspirations in a given dimension (by raising the poverty line above what is perceived as necessary to 'get by'), rather than trying to add to, or take away from, someone else's list of intrinsically valuable capabilities, which is a far more problematic exercise. ${ }^{34}$

Evidence from the latest econometric studies utilizing panel data shed additional light on adaptation, as they can be used to help identify causal relationships. These studies suggest that people who experience reductions in income are less satisfied than those with stable incomes, as they compare their current (lower) income with previous experience. Those who experience an increase in income, on the other hand, are no more satisfied in the long run, as they become increasingly accustomed to higher consumption levels and strive to keep up with the rest of society. This form of adaptation is very different from the one that has gained currency in development ethics and among proponents of the CA. It does not sit well with the idea that people's wants, hopes and aspirations are crushed by the harsh realities of poverty and deprivation. Nor is it

\footnotetext{
${ }^{33}$ Stutzer (2004, p.98), for example, found that on average a 10 percent increase in household income is associated with a 4.5 percent increase in 'minimum required income' in his analysis of Swiss data.

${ }^{34}$ This is because there is no way of knowing for sure which 'missing' capabilities would be endorsed (or rejected) by a particular person, group or society in the absence of adaptation. It follows that any attempt to 'amplify' the voices of the poor should focus on raising the threshold in approved dimensions of well-being instead of attempting to broaden the concept of well-being to include new capabilities. In this respect the process of amplifying the voices of the poor is incomplete (like many aspects of the CA). One way of extending this approach to include 'missing' capabilities might involve appealing to the values and experiences of other cultures and societies through some form of internal deliberation. I have considered the potential pitfalls of this approach above.
} 
consistent with the notion that aspirations are conditioned by some form of social, cultural or religious indoctrination (in which case, we would not expect aspirations to depart much from the established 'norm').

Arguably adapting aspirations upwards - instead of downwards - to reflect 'what is seen as possible' has far less serious consequences for investigating human values and listening to the ambitions and aspirations of the poor. ${ }^{35}$ Raising aspirations in the light of new possibilities or meaningful comparisons with others is a much more healthy exercise than reducing wants in the face of personal hardship. In cases where actual income declines, we should be less concerned about people who respond by raising income aspirations (as recent econometric evidence suggests), than those who rapidly reduce aspirations to avoid bitter disappointment. Crucially, raising aspirations to reflect previous achievements or meaningful social comparisons strengthens the case for listening to the poor. This is good news for development studies and those striving to develop a participatory version of the CA. Ironically, however, some development ethicists and capability theorists have invested heavily in critiques of the very processes that drive aspirations upwards in consumer societies (e.g. Nussbaum, 1988; Crocker and Linden, 1998; Gasper, 2002).

\section{Summary and Final Remarks}

The idea that people adapt to poverty and deprivation by learning to suppress their wants, hopes and aspirations has gained a great deal of currency in development ethics (e.g. Sen,

\footnotetext{
${ }^{35}$ There are other more powerful arguments for listening to the poor. Ultimately, giving everyone a say, including the poor, is a matter of social justice.
} 
1987b; Crocker, 1992; Nussbaum and Sen, 1993; Nussbaum and Glover, 1995; Nussbaum, 2000). In particular, this line of thought is frequently cited as a reason for moving away from utilitarian inspired concepts of well-being based on happiness or the fulfillment of desires. However, more rests on the adaptation argument than is often recognized. As we have seen, adaptation may pose serious problems for making the CA operational, if the relevant capabilities are to be identified through democratic or participatory techniques (e.g. Sen, 1999; 2005a; Alkire, 2002; Clark, 2002b). More generally, the adaptation argument may undermine the moral case for listening to the poor, which would leave the entire participatory poverty research movement in limbo (e.g. Chambers, 1997; Narayan et al, 2000, 2002; Ramphele, 2006). Nor can we fall back on the revealed preference approach as a guide to well-being if people's abilities, behavior and choices are shaped by the experience of poverty (as Qizilbash, 1997a suggests). In short, the implications of adaptation for development theory and practice seem grim.

However, the available evidence indicates that adaptation is not universal. Aspirations do not systematically adapt to reflect objective circumstances or living conditions for all people. Nor do aspirations adjust across all domains of well-being. Moreover, the most reliable evidence based on econometric analyses of panel data suggests that when adaptation does occur, it takes a different form (i.e. raising aspirations to reflect new possibilities) from the type commonly discussed in the capability and well-being literature (reducing aspirations to reflect straitened circumstances). ${ }^{36}$ I have argued that

\footnotetext{
${ }^{36}$ Admittedly further research is required as most of the available econometric evidence focuses exclusively on income or expenditure.
} 
this second type of adaptation is a healthier form of psychological adjustment and less worrying from the perspective of making the CA operational and investigating the values and aspirations of the poor.

The CA can also take comfort from the fact that not everything hangs on the adaptation argument. While adaptation is often cited as one of the principal arguments for abandoning utility based concepts of well-being in favor of the CA, it is not the only argument for doing so (see Crocker, 1992; Alkire, 2002; Clark, 2002b, pp.31-4). Indeed, Sen (1982, p.302) himself argues that the relevance of non-utility information 'is the central issue involved in disputing welfarism [i.e., utility],. ${ }^{37}$ It follows that it is entirely possible to be skeptical of the adaptation argument from a capability and human development perspective. In fact, if the available evidence is weighed carefully - and we as ethical theorists believe with Sen that any reasonable list of capabilities should be forged by the people directly concerned - I would be inclined to argue that the adaptation argument should be viewed with caution. The million dollar question is why are so many development ethicists, capability theorists and proponents of human need so obsessed with the adaptation problem? In some cases at least, part of the answer is that the adaptation argument can be used either consciously or sub-consciously to justify and privilege elitist conceptions of well-being and development. ${ }^{38}$ This is especially true of virtue ethics (which emphasize notions of 'excellence' and 'flourishing') and some

\footnotetext{
${ }^{37}$ The CA can also take comfort from the fact that both types of adaptation mentioned above suggest that utility is a bad proxy for human well-being. On this see Burchardt (2005).

${ }^{38}$ More often than not such views are expressed informally in seminars and workshops or behind closed doors rather than in scholarly writings.
} 
theories of human need (particularly those which emphasize 'genuine' or 'authentic' needs). ${ }^{39}$

\section{Acknowledgement}

This is a substantially revised and shortened version of a paper presented at the Sixth International Conference of the Human Development and Capability Association (HDCA) in Groningen, The Netherlands, 29 August - 1 September 2006. A later version of this paper was presented at the Global Poverty Research Group workshop, University of Oxford, 11 December 2006. The author is grateful to Abigail Barr, David Hulme, Marcel Fafchamps, Richard Jolly, Daniel Neff, Mozaffar Qizilbash, two anonymous referees, conference delegates and workshop participants for helpful comments and suggestions.

\section{References}

Alkire, S. (2002), Valuing Freedoms: Sen's Capability Approach and Poverty Reduction, Oxford University Press, Oxford.

Anti-Slavery International (2003), 'Slavery in Niger', submission to the United Nations Commission on Human Rights, Anti-Slavery International, London. Available online http://www.antislavery.org/archive/submission/submission2003-niger.htm (Accessed 19 July 2007).

Baran, P. and Sweezy, P. (1966), Monopoly Capital, Monthly Review Press, London.

Barr, A. and Clark, D.A. (2006), 'A Multidimensional Analysis of Adaptation in a Development Country Context', GPRG Conference on Equity, Opportunity and Identity, St Catherine's College, Oxford, 19 March 2006.

Bottomore, T. (ed.) (1983), 'Class Consciousness', 'Idealism' and 'Ideology' in A Dictionary of Marxist Thought, Basil Blackwell, Oxford.

\footnotetext{
${ }^{39}$ Elsewhere I have criticised Baran and Sweezy's (1966) account of 'genuine human need' (Clark, 2002b, pp.55-58) and Goulet's (1997) interpretation of 'scaled needs' (Clark, 2002a) on the grounds that they are objectionably paternalistic. Doyal and Gough's (1991) influential theory of human need not only tells us which basic needs must be fulfilled, but goes on to prescribe 'universal satisfiers' for meeting these needs. For a thought provoking critique of Doyal and Gough’s approach see Soper (1993).
} 
Burchardt, T. (2005), ‘Are One Man’s Rags Another Man’s Riches? Identifying Adaptive Expectations Using Panel Data', Social Indicators Research, 74, pp. 57-102.

Camfield, L. and Skevington, S. (forthcoming), 'Quality of Life and Well-Being', unpublished, University of Bath, UK.

Chambers, R. (1997), Whose Reality Counts? Putting the First Last, ITDG Publishing, India.

Chan, A., Ofstedal, M. B., and Hermalin, A. I. (2002), 'Changes in Subjective and Objective Measures of Economic Well-Being and Their Interrelationship Among the Elderly in Singapore and Taiwan', Social Indicators Research, 57, pp. 263300.

Clark, D.A. (2002a), 'Development Ethics: A Research Agenda', International Journal of Social Economics, 29(11), pp. 830-848.

Clark, D.A. (2002b), Visions of Development: A Study of Human Values, Edward Elgar, Cheltenham.

Clark, D.A. (2003), 'Concepts and Perceptions of Human Well-Being: Some Evidence from South Africa', Oxford Development Studies, 31(2), pp. 173-196.

Clark, D.A. (2005), 'Sen's Capability Approach and the Many Spaces of Human WellBeing', Journal of Development Studies, 41(8), pp. 1339-1368.

Clark, D.A. (2006a), ‘Capability Approach’ in D.A. Clark (ed.), The Elgar Companion to Development Studies, Edward Elgar, Cheltenham, pp. 32-45.

Clark, D.A. (2006b), 'Introduction: Development Studies in the Twenty First Century' in D.A. Clark (ed.), The Elgar Companion to Development Studies, Edward Elgar, Cheltenham, pp. xxvi-xli.

Clark, D.A. and Qizilbash, M. (2007), 'Core Poverty, Vagueness and Adaptation: A New Methodology and Some Results for South Africa', Journal of Development Studies, forthcoming.

Cohen, G.A. (1993), 'Equality of what? On welfare, goods and capabilities', in M.C. Nussbaum and A.K. Sen (eds), The Quality of Life, Clarendon Press, Oxford, pp. 9-29.

Crocker, D. (1992), 'Functioning and Capabilities: The Foundation of Sen's and Nussbaum's Development Ethic', Political Theory, 20(4), pp. 584-612.

Crocker, D. (2006), 'Sen and Deliberative Democracy' in A. Kaufmann (ed.), Capabilities and Equality: Basic Issues and Problems, Routledge, New York, pp. 155-97.

Crocker, D. and Linden, T. (eds) (1998), Ethics of Consumption: The Good Life, Justice, and Global Stewardship, Rowman \& Littlefield, Oxford.

Deneulin, S. (2005), 'Promoting Human Freedoms Under Conditions of Inequalities: A Procedural Framework', Journal of Human Development, 6(1), pp. 75-92.

Diener, E., Suh, E.M., Lucas, R.E. and Smith, H.L. (1999), 'Subjective Well-Being: Three Decades of Progress', Psychological Bulletin, 125(2), pp. 276-302.

Diener, E. and Suh, E.M. (eds) (2000), Culture and Subjective Well-Being, MIT Press, Cambridge MA.

Doyal, L. and Gough, I. (1991), A Theory of Human Need, Macmillan, London.

Drèze, J. and Sen, A.K. (1989), Hunger and Public Action, Clarendon Press, Oxford.

Easterlin, R. (1974), 'Does Economic Growth Improve the Human Lot? Some Empirical Evidence', in P.A David M.W. Reder (eds), Nations and Households in Economics Growth: Essays in Honour or Moses Abramowitz, Academic Press, New York, pp. 89-125.

Easterlin, R.A. (2001), 'Income and Happiness: Towards A Unified Theory', Economic Journal, 111, pp. 465-484.

Easterlin, R.A. (2005), ‘A Puzzle for Adaptive Theory’, Journal of Economic Behavior and Organization, 56, pp. 513-521. 
Elster, J. (1982), 'Sour Grapes - Utilitarianism and the Genesis of Wants', in A.K. Sen and B. Williams (eds), Utilitarianism and Beyond, Cambridge University Press, Cambridge, pp. 219-38.

Elster, J. (1983), Sour grapes: Studies in the Subversion of Rationality, Cambridge University Press, Cambridge.

Frederick, S. and Loewenstein, G. (1999), 'Hedonic Adaptation' in D. Khaneman, E. Diener and N. Schwarz (eds), Well-Being: The Foundations of Hedonic Psychology, Russell Sage Foundation, New York, pp. 302-373.

Frey, B.S. and Stutzer, A. (2002), 'What Can Economists Learn from Happiness Research?', Journal of Economic Literature, 40, pp. 402-435.

Fukuda-Parr, S. (2003), 'The Human Development Paradigm: Operationalizing Sen's Ideas on Capabilities', Feminist Economics, 9(2-3), pp. 301-317.

Fukuda-Parr, S. and Kumar, A.K.S. (eds) (2003), Readings in Human Development, Oxford University Press, Oxford and New Delhi.

Garstang (2007), 'Slavery Today', Garstang Fair Trade Website, www.garstangfairtrade.org.uk/slavery_today.htm (accessed 9 August 2007).

Gasper,D. (2002), 'Is Sen's Capability Approach An Adequate Basis for Considering Human Development?', Review of Political Economy, 14 (4), pp. 435-61.

Goulet, D. (1971), The Cruel Choice: A New Concept in the Theory of Development, Atheneum, New York.

Goulet, D. (1997), 'Development Ethics: A New Discipline', International Journal of Social Economics, 24(11), pp. 1160-71.

Gregory, C. (2006), 'Hill, Polly (1910-2005)' in D.A. Clark (ed.), The Elgar Companion to Development Studies, Edward Elgar, Cheltenham, pp. 223-226.

Haq, M. ul (1995), Reflections on Human Development, Oxford University Press, Oxford.

Kahneman, D., Diener, E. and Schwarz, N. (eds) (1999), Well-Being: The Foundations of Hedonic Psychology, Russell Sage Foundation, New York.

Kingdon, G.G. and Knight, J. (2006), 'Subjective Well-Being Poverty vs. Income Poverty and Capabilities Poverty?', Journal of Development Studies, 42(7), pp. 1199-1224.

Moller, V. (ed.) (1996), Perceptions of Development in Kwa-Zulu Natal, Social Indicators Press, Durban.

Narayan, D., Patel, R., Schafft, K., Rademacher, A. and Koch-Schulte, S. (2000), Voices of the Poor: Can Anyone Hear Us?, Oxford University Press for the World Bank, Oxford.

Narayan, D. and Petesch, P. (2002), Voices of the Poor: From Many Lands, Oxford: Oxford University Press for the World Bank, Oxford.

Nussbaum, M.C. (1988), 'Nature, Function and Capability: Aristotle on Political Distribution', Oxford Studies in Ancient Philosophy, Supl. Vol., pp. 145-84.

Nussbaum, M.C. (2000), Women and Human Development: the Capabilities Approach, Cambridge University Press, Cambridge.

Nussbaum, M.C. (2001), 'Adaptive Preferences and Women’s Options', Economics and Philosophy, 17, pp. 67-88.

Nussbaum, M.C. (2006), 'Education and Democratic Citizenship: Capabilities and Quality Education', Journal of Human Development, 7(3), pp. 385-395.

Nussbaum, M.C. and Glover, J. (eds) (1995), Women, Culture and Development, Clarendon Press, Oxford.

Nussbaum, M.C. and Sen, A.K. (1989), 'Internal Criticism and Indian Rationalist Traditions', in Michael Krausz (ed.) Relativism, Interpretation and Confrontation, University of Notre Dame Press, South Bend, pp. 299-325. 
Nussbaum, M.C. and Sen, A.K. (eds) (1993), The Quality of Life, Clarendon Press, Oxford.

Okin, S.M. (2003), 'Poverty, Well-Being, and Gender: What Counts, Who's Heard?', Philosophy and Public Affairs, 31(3), pp. 280-316.

Qizilbash, M. (1997a), 'A Weakness of the Capability Approach with Respect to Gender Justice', Journal of International Development, 9(2), pp. 251-62.

Qizilbash, M. (1997b), 'Well-Being and Despair: Dante’s Ugolino', Utilitas, 9(2), pp. 227-240.

Qizilbash, M. (2006a), 'Capability, Adaptation and Happiness in Sen and J. S. Mill', Utilitas, 18(1), pp. 20-32.

Qizilbash, M. (2006b), 'Human Development' in D.A. Clark (ed.), The Elgar Companion to Development Studies, Edward Elgar, Cheltenham, pp. 245-250.

Qizilbash, M. (2006c), 'Well-Being, Adaptation and Human Limitations', Royal Institute of Philosophy Supplements, 81, pp. 83-110.

Ramphele, M. (2006), 'Poverty, Characteristics of' in D.A. Clark (ed.), The Elgar Companion to Development Studies, Edward Elgar, Cheltenham, pp. 465-468.

Robeyns, I. (ed.) (2006), 'Bibliography on the Capability Approach, 2005-2006', Journal of Human Development, 7(3), pp. 417-421.

Robeyns, I. (ed.) (2007), 'Bibliography on the Capability Approach, 2006-2007', Journal of Human Development, 8(3), pp. 481-486.

Rodriguez, J.P. (ed.), (2007), Encyclopedia of Slave Resistance and Rebellion, Greenwood, Westport, CT.

Ryan, R.M. and Deci, E.L. (2001), 'On Happiness and Human Potentials: A Review of Research on Hedonic and Eudaimonic Well-Being', Annual Review of Psychology, 52, pp. 141-66.

Ryff, C.D. (1989), 'Happiness is Everything, or Is It? Explorations on the Meaning of Psychological Well-Being', Journal of Personality and Social Psychology, 57(6), pp. 1069-81.

Saith, R. (2001), 'Capabilities: the Concept and its Operationalisation', QEH Working Paper Series 66, Queen Elizabeth House, University of Oxford.

Sandven, T. (1999a), 'Autonomy, Adaptation, and Rationality - A Critical Discussion of Jon Elster's Concept of “Sour Grapes,” Part I', Philosophy of the Social Sciences, 29(1), pp. 3-31.

Sandven, T. (1999b), 'Autonomy, Adaptation, and Rationality - A Critical Discussion of Jon Elster's Concept of "Sour Grapes," Part II', Philosophy of the Social Sciences, 29(2), pp. 173-205.

Sen, A.K. (1980), 'Equality of What?’ in S.M. McMurrin (ed.), The Tanner Lectures on Human Values, Cambridge University Press, Cambridge, pp. 195-220. Available online at http://www.tannerlectures.utah.edu/lectures/sen80.pdf

Sen, A.K. (1982), Choice, Welfare and Measurement, Basil Blackwell, Oxford.

Sen, A.K. (1984), Resources, Values and Development, Basil Blackwell, Oxford.

Sen, A.K. (1985a), Commodities and Capabilities, Elsevier Science Publishers, Oxford.

Sen, A.K. (1985b), 'Well-being, Agency and Freedom: the Dewey Lectures', Journal of Philosophy, 82(4), pp. 169-221.

Sen, A.K. (1987a), On Ethics and Economics, Blackwell, Oxford.

Sen, A.K. (1987b), The Standard of Living: The Tanner Lectures, Cambridge University Press, Cambridge. 
Sen, A.K. (1990), 'Development as Capability Expansion' in K. Griffin and J. Knight (eds), Human Development and the International Development Strategy for the 1990s, Macmillan, London, pp. 41-58.

Sen, A.K. (1992), Inequality Reexamined, Clarendon Press, Oxford.

Sen, A.K. (1993a), 'Capability and Well-being' in M.C. Nussbaum and A.K. Sen (eds), The Quality of Life, Clarendon Press, Oxford, pp. 30-53.

Sen, A.K. (1993b), 'Positional Objectivity', Philosophy and Public Affairs, 22(2), pp. 127-145.

Sen, A.K. (1999), Development As Freedom, Oxford University Press, Oxford.

Sen, A.K. (2002), 'Health: Perception versus Observation’, British Medical Journal, 324, pp.860-861.

Sen, A.K. (2004), 'Capabilities, Lists and Public Reason: Continuing the Conversation', Feminist Economics, 10(3), pp. 77-80.

Sen, A.K. (2005a), 'Human Rights and Capabilities', Journal of Human Development, 6(2), pp. 151-66.

Sen, A.K. (2005b), The Argumentative Indian: Writings on Indian Culture, History and Identity, Penguin, London.

Sen, A.K. (2006a), 'Human Development Index', in D.A. Clark (ed.), The Elgar Companion to Development Studies, Edward Elgar, Cheltenham, pp. 256-260.

Sen, A.K. (2006b), 'Reason, Freedom and Well-Being', Utilitas, 18(1), pp. 80-96.

Sen, A.K. and B. Williams (eds) (1982), Utilitarianism and Beyond, Cambridge University Press, Cambridge.

Soper, K. (1993), 'Review: A Theory of Human Need', New Left Review, 197, pp. 113128.

Stutzer, A. (2004), 'The Role of Income Aspirations in Individual Happiness', Journal of Economic Behavior and Organization, 54, pp. 84-109.

Sugden, R. (2006), 'What We Desire, What We Have Reason to Desire, Whatever We Might Desire: Mill and Sen on the Value of Opportunity', Utilitas, 18(1), pp. 3351.

Sumner, L.W. (1996), Welfare, Happiness and Ethics, Clarendon Press, Oxford.

Teschl, M. and Comim, F. (2005), 'Adaptive Preferences and Capabilities: Some Preliminary Conceptual Explorations’, Review of Social Economy, 63(2), pp. 229247.

Williamson, J. (2003), 'Lady Bountiful Tries Life in the Slums', New Statesman, 20, pp. 25-26.

Winkelmann, L. and Winkelmann, R. (1998), 'Why are the unemployed so unhappy? Evidence from panel data', Economica, 65, pp. 1-15.

Young, I.M. (2006), 'Public Debate and Social Justice', Maitreyee, No. 4 (February), Newsletter of the Human Development and Capability Association. 